\title{
Rotational Behavior of Column Footing Joint and Its Effect on the Dynamic Characteristics of Traditional Chinese Timber Structure
}

\author{
Shujie Qin $\mathbb{D}^{D}$, Na Yang $(\mathbb{D}$, and Lu Dai \\ School of Civil Engineering, Beijing Jiaotong University, Beijing 100044, China \\ Correspondence should be addressed to Na Yang; nyang@bjtu.edu.cn
}

Received 5 March 2018; Revised 2 June 2018; Accepted 11 June 2018; Published 5 July 2018

Academic Editor: Sergio De Rosa

Copyright (C) 2018 Shujie Qin et al. This is an open access article distributed under the Creative Commons Attribution License, which permits unrestricted use, distribution, and reproduction in any medium, provided the original work is properly cited.

\begin{abstract}
Chinese heritage timber buildings are of high historical and cultural values. The column footing joint is an important connection influencing the structural performance under dynamic load. The moment-rotation relationship of a column footing joint is studied and the effects of vertical load and ratio of column height to diameter on its rotational behavior are analyzed. A spring elements model is proposed to simulate the column footing joint and its stiffness matrix can be simplified to include only one stiffness parameter $K$ with some assumptions. A component-based finite-element model of a timber pavilion is then developed to investigate the effect of rotational stiffness on the structural dynamic characteristics. Results show that a heavier vertical load may lead to larger ultimate moment capacity of the joint. The initial rotational stiffness and ultimate moment capacity decrease with increasing column height to diameter ratio. The modal frequency of the structure studied changes remarkably when the rotational stiffness $K$ varies from $10^{4}$ to $10^{8} \mathrm{~N}=\mathrm{m} / \mathrm{rad}$. The column footing joints should be regarded as semirigid connections in the structural dynamic analysis. A field experiment was also conducted to further demonstrate that the rotational stiffness of column footing joint has notable influence on the dynamic characteristics of traditional Chinese timber structure.
\end{abstract}

\section{Introduction}

Traditional Chinese timber architecture is an important part of the Chinese civilization with high historical, cultural, and artistic values. Many of them have been classified as heritage sites, such as the Yingxian Wooden Pagoda (built in 1056), Fogong Temple (built in about 471), and the Forbidden City (built in 1420). These heritage buildings have experienced different types and extent of damage $[1,2]$ with reduced mechanical properties of material $[2,3]$ after hundreds of years. There is an urgent need to clearly understand their structural performances so that scientific and effective measures can be taken for the protection and maintenance of these historical structures.

The history of timber structures in China dates back to at least three thousand years in the era of the Chinese Zhou Dynasty (1100-256 BC) [4]. The construction and structural form of timber structure evolved with time with the most spectacular design in Tang Dynasty (618-907 AD). Detailed specifications of the connections and components in timber structures were formally stipulated in perhaps the earliest official building code, the Ying Zao Fa Shi (Guidance and Stipulations of Construction) in $1103 \mathrm{AD}$, in the era of the Song Dynasty (960-1279 AD) [5]. The structural components became smaller and more exquisite with rich colorful paintings on the surfaces in the Ming Dynasty and Qing Dynasty (1368-1912 AD). Field investigations and historical records on existing wooden buildings show that the Chinese timber structures can be broadly classified into two types, i.e., Song style architecture and Ming-Qing style architecture [6]. Liang [4] and Ma [6] investigated the construction methods and architectural characteristics of these structures. Wang [7] systematically analyzed the distribution and transmission of the vertical loads in timber structural members and it has become a good reference for later studies.

Traditional Chinese timber structures often consist of beams and columns with large cross sections connected by joints including the Dou Gong (corbel bracket), mortisetenon joint, and the column footing joint (CFJ) [4]. These joints are the weakest links of the structure and they are 
TABLE 1: Modal frequency of typical Chinese heritage timber buildings (Hz).

\begin{tabular}{lccccc}
\hline $\begin{array}{l}\text { Yingxian Wood Pagoda } \\
{[27]}\end{array}$ & $\begin{array}{c}\text { The front tower over the North } \\
\text { Gate of Xi'an City Wall [28] }\end{array}$ & $\begin{array}{c}\text { Jixian Dule } \\
\text { Temple [29] }\end{array}$ & $\begin{array}{c}\text { Happiness Palace in the Forbidden City [30] } \\
\text { Main hall }\end{array}$ & $\begin{array}{c}\text { Back hall } \\
\text { Eastern side } \\
\text { hall }\end{array}$ & $\begin{array}{c}\text { Western side } \\
\text { hall }\end{array}$ \\
\hline 0.64 & 1.45 & 1.37 & 1.26 & 1.42 & 1.48 \\
\hline
\end{tabular}

always a research focus [8, 9]. Some significant researches have been done in recent years on the structural behavior of CFJ. Zhang [10] measured the frictional coefficient of the contact surface between the column and the supporting base stone. Yao and Zhao [11] developed a friction-sliding seismic isolation model and they proposed a criterion on the slippage of the column foot. Xue et al. [12] studied the shock absorption and isolation performance of CFJ by shaking table test, and they found that the sliding of column foot could reduce the seismic response of the timber structure. Lee et al. [13] presented a technique to obtain the skeleton curve of moment-rotation relationship of a CFJ by compression test of timber components. Maeno et al. [14] conducted experimental study on the column rocking behavior and they concluded that the restoring moment of a rocking column mainly comes from the top and bottom of the column. Assuming that both the column top and bottom have the same stress state, Zhang et al. [15] estimated the restoring moment at the column foot with reference to the restoring moment at the column top. When the restoring moment is greater than certain level, the beam-column frame overturns [16]. He et al. [17] experimentally investigated the characteristics of column movement, its deformation, and the loaddisplacement hysteretic curve during rocking under repeated horizontal load. A theoretical model on the restoring moment of a CFJ with consideration of the compression effect was proposed [18] and the evolution of the working states of the joint with increasing horizontal load was analyzed. Research on Dou Gong and mortise-tenon joint is much more than that on CFJ. The structural performance of Dou Gong [19-21] and mortise-tenon joint [22-24] in terms of the stiffness, loadcarrying capacity, mechanism of deformation, and energydissipation has been studied. The degradation on the load resistance of Dou Gong and mortise-tenon joint has also been investigated experimentally with artificial induced damage to simulate three types of local damage caused by corrosion, insect, and crack, respectively $[25,26]$.

Natural frequency is one of the more popular structural parameters related to the condition of the structure $[8,9]$. The in situ fundamental frequency of several typical Chinese heritage timber buildings [27-30] is summarized in Table 1. They are different for different timber buildings with a range of 0.64 to $1.61 \mathrm{~Hz}$. This is due to the different types of construction and different extent of damage incurred in the building after hundreds of years of service. The fundamental frequency basically decreases with increasing height of the building. For example, Yingxian Wooden Pagoda with 65.86 $\mathrm{m}$ height has a lower natural frequency than other buildings.

Numerous studies on the dynamic properties and responses of traditional timber structures have also been conducted. Fang et al. [28] carried out multiple excitation tests on a scaled wooden model of the front tower at the North Gate of Xi'an City Wall with comparison of both the numerical and experimental vibration mode shapes. Chen et al. [31] studied the behavior of Yingxian Wooden Pagoda under wind load, and they found that strong wind is one of the main reasons to account for the permanent inclination of the structure. Zhang et al. [32] proposed a frequency domain method to predict the vibration of historical timber building under traffic loads with application to the vibration of Yangzhou Zhunti Temple. Dai et al. [33] conducted field measurements on the modal parameters and damping ratio of a typical Tibetan timber wall-frame building. The seismic performance of a scaled timber structure model was investigated [11, 12, 34, 35] including the hysteretic curve, stiffness degradation, failure modes, natural frequency, damping ratio, and the energy-dissipation mechanism in low cyclic loading tests and shake table tests.

Since the construction of Dou Gong and mortise-tenon joint is complicated, the timber connections are usually simplified as semirigid joints in analyzing the timber structures. A series of studies on the dynamic properties and earthquake responses of traditional Chinese timber structures [36-39] have been conducted with these joints modeled as semirigid joints in three-dimensional (3D) finite-element models (FEMs). The stiffness parameters of these joints are often determined numerically or from experiments [1926]. Few studies are found on the rotational behavior of CFJ in traditional Chinese timber structure. The CFJ is usually regarded as being hinged without consideration of its rotational stiffness [36-39].

The main features of traditional Chinese timber structure and the types of column footing joint are firstly introduced in this paper. The moment-rotation relationship of a CFJ is then investigated based on a refined FEM. The effects of vertical load and the ratio of column height to diameter on the rotational stiffness are analyzed. A 3D spring elements model is developed for the component-based FEM for the dynamic analysis of a timber structure. A dynamic field test is also conducted to validate the effect of rotational stiffness of the CFJ on dynamic characteristics of traditional Chinese timber structures.

\section{Construction of a CFJ}

The traditional Chinese timber structure is typically an assembled structure with components connected by three types of joints including the Dou Gong, mortise-tenon joint, and CFJ [4]. The structure can be conveniently divided into four layers from top to bottom, i.e., the roof layer, Dou Gong layer, column frame layer, and the basement layer as shown in Figure 1. Traditional Chinese timber structure features a 


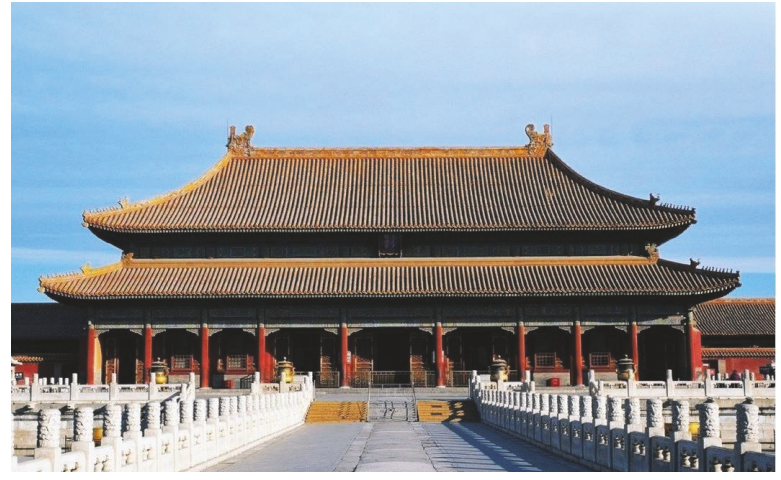

(a)

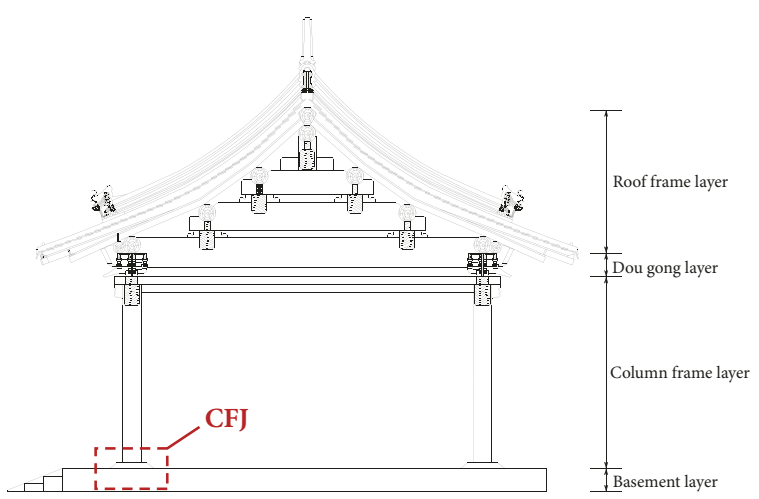

(b)

FIGURE 1: Typical traditional Chinese timber structure: (a) appearance; (b) constructional schematic.

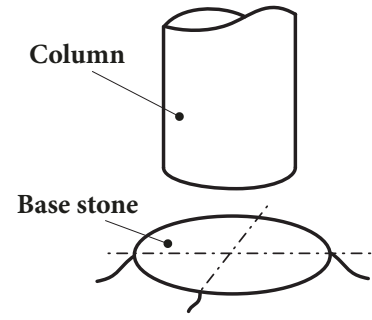

(a)

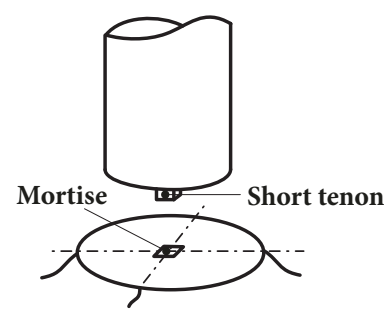

(b)

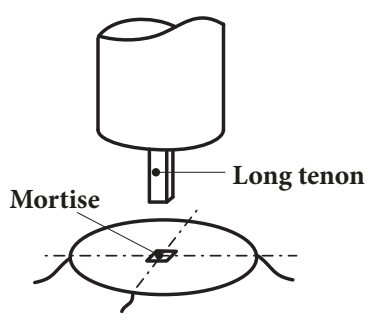

(c)

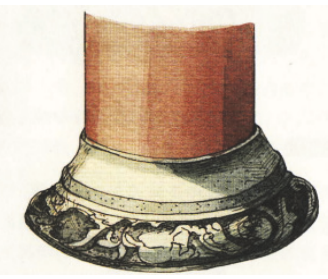

(d)

Figure 2: Different forms of Chinese-type CFJ: (a) Floating; (b) Guan-jiao; (c) Tao-ding; (d) appearance.

heavy roof with its weight passing down different layers and transferred to the column foots.

$\mathrm{CFJ}$ is a key component connecting the upper timber frame and the lower plinth of structures as shown in Figure $1(\mathrm{~b})$. It has been playing a vital role in bearing the selfweight and resisting different kinds of external load including earthquake, wind, and some other human-induced load for hundreds of years of its existence. The column, often shaped in circular cross section, is simply supported by a base stone without any nail or bracing. There are different types of construction of the column and the base stone (Figure 2), and the CFJ can be classified into three types following the traditional Chinese naming system:

(1) Floating: the column is placed on the base stone without tenon, and the horizontal external load is resisted by the friction between column end and the base stone as shown in Figure 2(a).

(2) Guan-jiao: the column is placed on the base stone with a short timber tenon to locate and center the position of the column foot at the time of installation, as shown in Figure 2(b).

(3) Tao-ding: the column is placed on the base stone with a long timber tenon that can bear a certain amount of bending moment and horizontal shear load, as shown in Figure 2(c).

The appearance of the three types of CFJs is similar as shown in Figure 2(d). Floating type is the most common form and it accounts for about 90\% [4] of the CFJs. In practice, decay and fungal attach of the timber tenon in the Guanjiao and Tao-ding types easily occur due to moisture in the environment and fungi during the service life of the timber structures. The timber tenon will lose its structural function with time and the Guan-jiao and Tao-ding will finally change into the form of Floating type. Therefore, this paper focuses on the mechanical performance of the Floating type CFJ. The interface of the joint only bears the compressive force from above the joint and it has no capacity for tension. When under horizontal load with the weight of heavy roof on top of the column, the column foot will rotate around its edge with uneven compressive deformation in the pressurebearing surface, which provides a restoring moment to resist the lateral displacement of the timber structure [14].

\section{Rotational Behavior of a CFJ}

3.1. Refined FEM and Model Validation. A refined threedimensional FEM is developed in ABAQUS software for the present study. The CFJ is modeled with eight-node brick elements with reduced integration (element type C3D8R) with sweep technology. The element mesh at the bottom of column is denser than those at other parts as shown in Figure 3. The bottom of the base stone is fixed, and the column is directly placed on top without any physical connection. The frictional coefficient of the contact interface between column and base stone ranges from 0.3 to 0.5 [10]. Coulomb friction model is adopted as the interface model in this study 
TABLE 2: : Material parameters of column.

\begin{tabular}{cccccc}
\hline \multicolumn{3}{c}{ Modulus of elasticity (MPa) } & \multicolumn{4}{c}{ Shear modulus (MPa) } \\
$E_{L}$ & $E_{R}$ & $E_{T}$ & $G_{L R}$ & $G_{L T}$ & $G_{T R}$ \\
\hline 11330 & 1133 & 566 & 850 & 680 & 204 \\
\hline
\end{tabular}

Note: $L, R$, and $T$ denote the grain, radial, and chordwise directions, respectively. The material density is $434 \mathrm{~kg} / \mathrm{m}^{3}$.

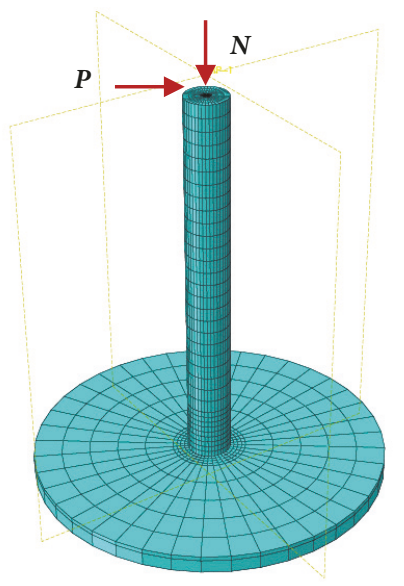

FIgURE 3: Finite-element model of CFJ.

to represent the tangential behavior at the column foot, and the frictional coefficient is taken as 0.4 . The loading program is divided into two parts: the specified vertical load $N$ is first applied on top of the column followed by the gradual application of horizontal displacement at the column top until the joint fails. The size of column is representative of those of traditional Chinese timber pavilions in the Forbidden City, and they are of $240 \mathrm{~mm}$ diameter and $2150 \mathrm{~mm}$ height. The timber is hardwood pine according to information provided by the management office of the Forbidden City. The material parameters of the column referred to those for hardwood pine in reference [40], as shown in Table 2. Elastic modulus of base stone is about ten times bigger than that of timber parallel to the grain and is regarded as rigid body in the analysis.

The computed horizontal load-displacement relationship obtained from the analysis with the above model is compared with the experimental curve [17] as shown in Figure 4. There is a reasonably good agreement in terms of the overall trend with some discrepancies in the initial stiffness, peak load, and the detail of the descending branch. Considering the different types of defects in the column and other practical details in practice, including the initial gap at the interface between column and base stone, the initial defects such as dryshrinkage cracks and timber knots in the real timber column, and the difference of material mechanical parameters in the FEM and real structures well as the experimental error during the loading process, the FE model is considered acceptable for the present study.

3.2. Moment-Rotation Relationship. The moment-rotation relationship of the CFJ is obtained as shown in Figure 5. The $x$ and $y$ axes represent the rotation angle and restoring

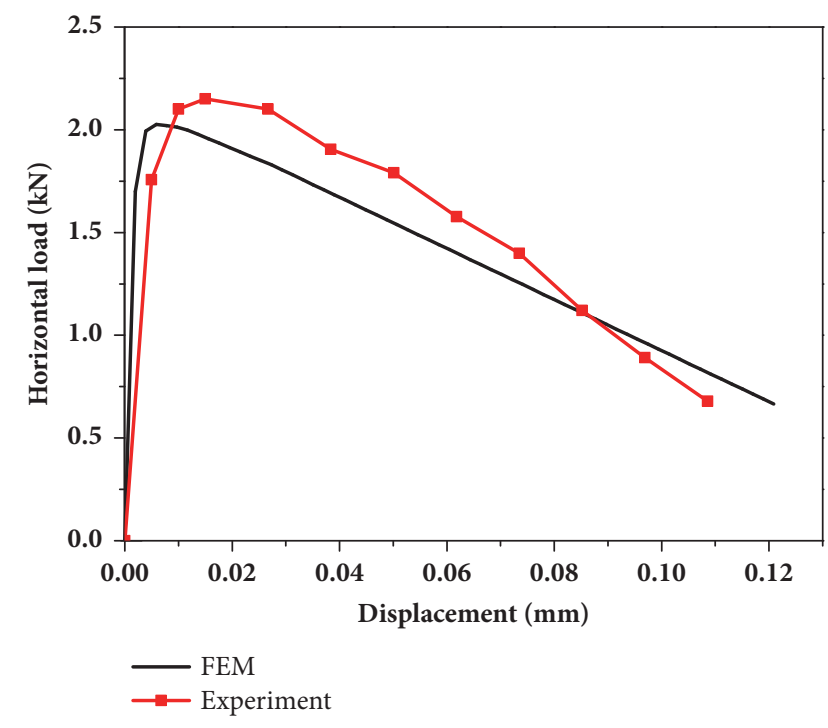

FIGURE 4: Comparison of load-displacement relationships between FEM and experimental results.

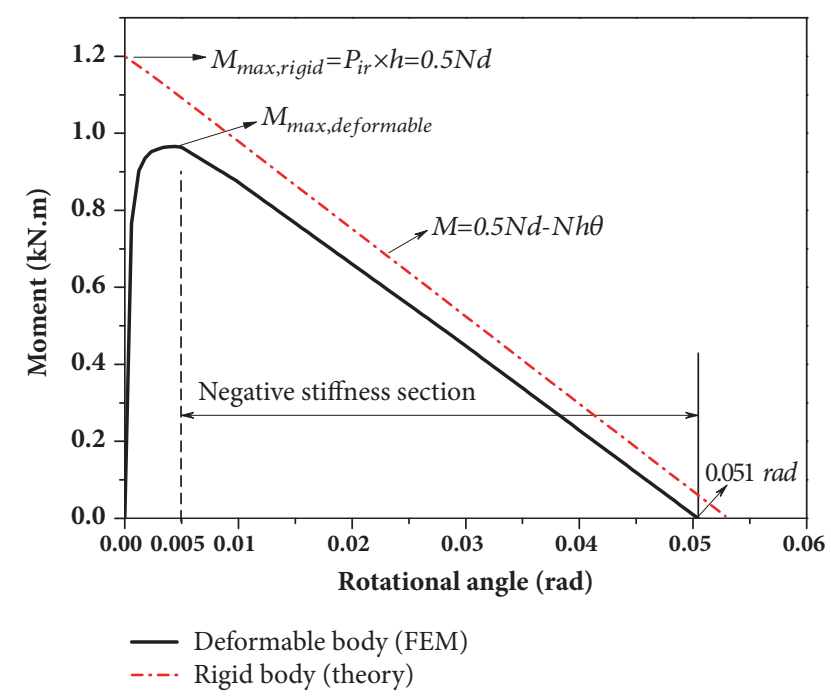

Figure 5: Moment-rotation curve.

moment, respectively, such that the slope of this curve represents the rotational stiffness of the joint. The restoring moment is calculated as $P \times 2.15 \mathrm{kN}=\mathrm{m}$ considering equilibrium of the column. It is noted that when the rotational angle is small, the rotational stiffness is relatively large and the restoring moment increases with the rotational angle. The stiffness gradually decreases with increasing rotational angle until the angle equals $0.005 \mathrm{rad}$ and the restoring moment reaches its maximum. The moment then decreases with increase of the rotational angle in the moment-rotation relationship. When the rotational angle increases to $0.051 \mathrm{rad}$, the restoring moment equals zero. It is noted that $0.051 \mathrm{rad}$ is close to the state where the horizontal displacement at the column top equals half of the column diameter; i.e., arctan $(0.5 d / h)=0.055 \mathrm{rad}$. After going beyond this point, both the horizontal and vertical loads will produce overturning 
moments, and the column will not be in equilibrium with imminent toppling. The beam-column joint in timber frame can, however, provide relatively large resisting moment in practice with large rotational angle of the column such that the column will not fall down suddenly in practice [14].

Figure 6 shows the moment-rotation curves of the CFJ with a vertical load of $10 \mathrm{kN}, 20 \mathrm{kN}$, and $30 \mathrm{kN}$, respectively, on the top of column. The initial rotational stiffness calculated from the initial linear section is $1310 \mathrm{kN}-\mathrm{m} / \mathrm{rad}, 1370$ $\mathrm{kN}=\mathrm{m} / \mathrm{rad}$, and $1410 \mathrm{kN}=\mathrm{m} / \mathrm{rad}$, respectively, for the different vertical load on top, and the ultimate moment capacities are, respectively, $0.97 \mathrm{kN} \cdot \mathrm{m}, 1.78 \mathrm{kN}-\mathrm{m}$, and $2.53 \mathrm{kN}-\mathrm{m}$. These indicate that the variation of vertical load has little effect on the initial rotational stiffness, while it has an obvious effect on the ultimate moment capacity. A heavier vertical load can lead to larger ultimate moment capacity of the column. The slope of the descending moment-rotation curve is getting steeper with the increase of vertical load indicating that the column has the poorer stability after exceeding the ultimate rotation angle under a greater vertical load on the top of the column.

To study the effect of the ratio of column height to diameter $(\eta=h / d)$ on the rotational behavior of CFJ, the column height is kept at $2150 \mathrm{~mm}$ whereas the column diameter takes up values of $200 \mathrm{~mm}, 240 \mathrm{~mm}$, and $280 \mathrm{~mm}$ in turn. The ratio $\eta$ equals $10.75,8.96$, and 7.68 , respectively, and the moment-rotation relationships of the CFJ are shown in Figure 7. The initial rotational stiffness values are $805 \mathrm{kN} \cdot \mathrm{m} / \mathrm{rad}, 1120 \mathrm{kN}=\mathrm{m} / \mathrm{rad}$, and $1480 \mathrm{kN}=\mathrm{m} / \mathrm{rad}$, respectively, for the different column height to diameter ratios. The ultimate moment capacities are, respectively, 0.77 $\mathrm{kN}=\mathrm{m}, 0.97 \mathrm{kN}=\mathrm{m}$, and $1.20 \mathrm{kN}=\mathrm{m}$. The ratio $\eta$ is found to have distinct influence on both the initial rotational stiffness and ultimate moment capacity which decrease with an increase of ratio $\eta$. However, the ratio $\eta$ does not affect the slope of the descending moment-rotation curve segment.

\section{Computational Model of a Semirigid Connection}

It is noted from Section 3.2 that a CFJ is not a hinge joint and it should be regarded as a semirigid joint with certain rotational stiffness. A 3D spring elements model (SEM) with six parameters including three rotational stiffness parameters and three axial stiffness parameters, as shown in Figure 8, is proposed to simulate the structural behavior of the CFJ. The SEM has neither mass nor dimension and it exists in a variety of forms including the extreme cases of a rigid joint or a hinge. Assuming that there is no coupled interaction between different spring elements, the stiffness matrix of the SEM can be written as

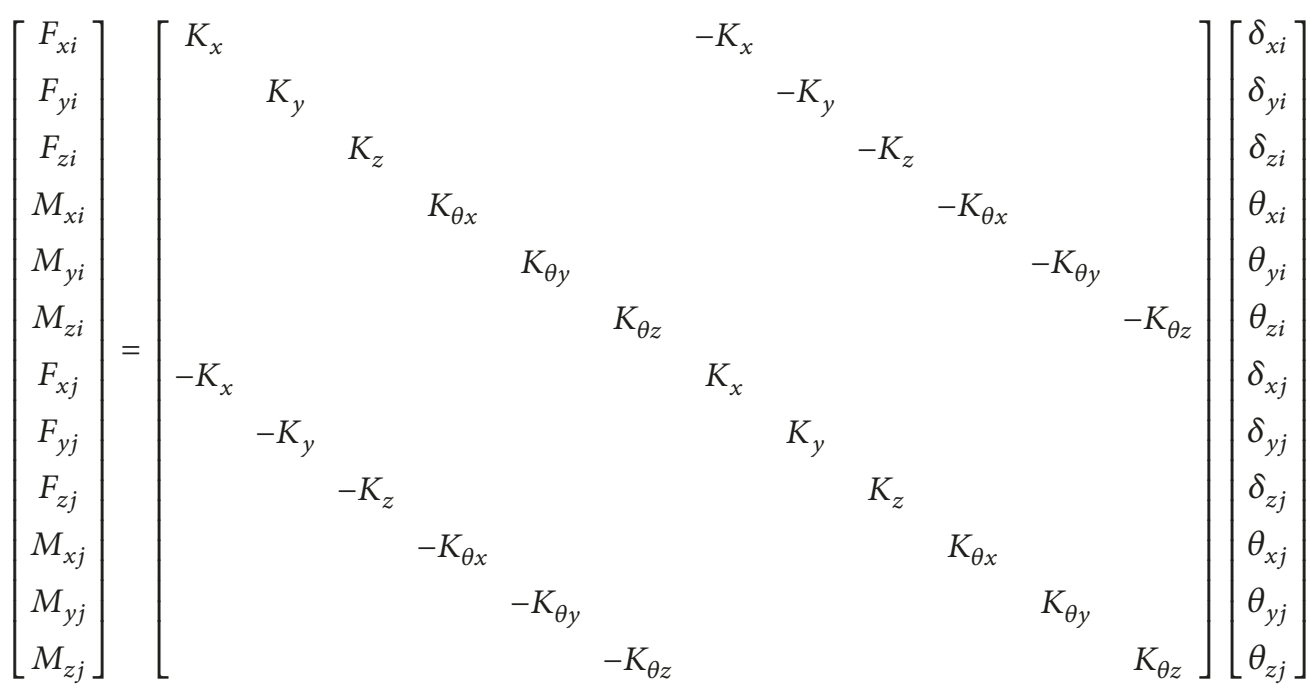

Columns in timber building are subjected to vertical load from the upper levels. When under horizontal load (such as wind load and earthquake action), the column foot may not slip until the horizontal load exceeds the static frictional resistance as

$$
f=\mu N
$$

where $N$ is the vertical load at the column top and $\mu$ is the static coefficient of friction at the interface between column and base stone. When the lateral friction force $P^{\prime}$ at the column bottom is smaller than the static frictional resistance 

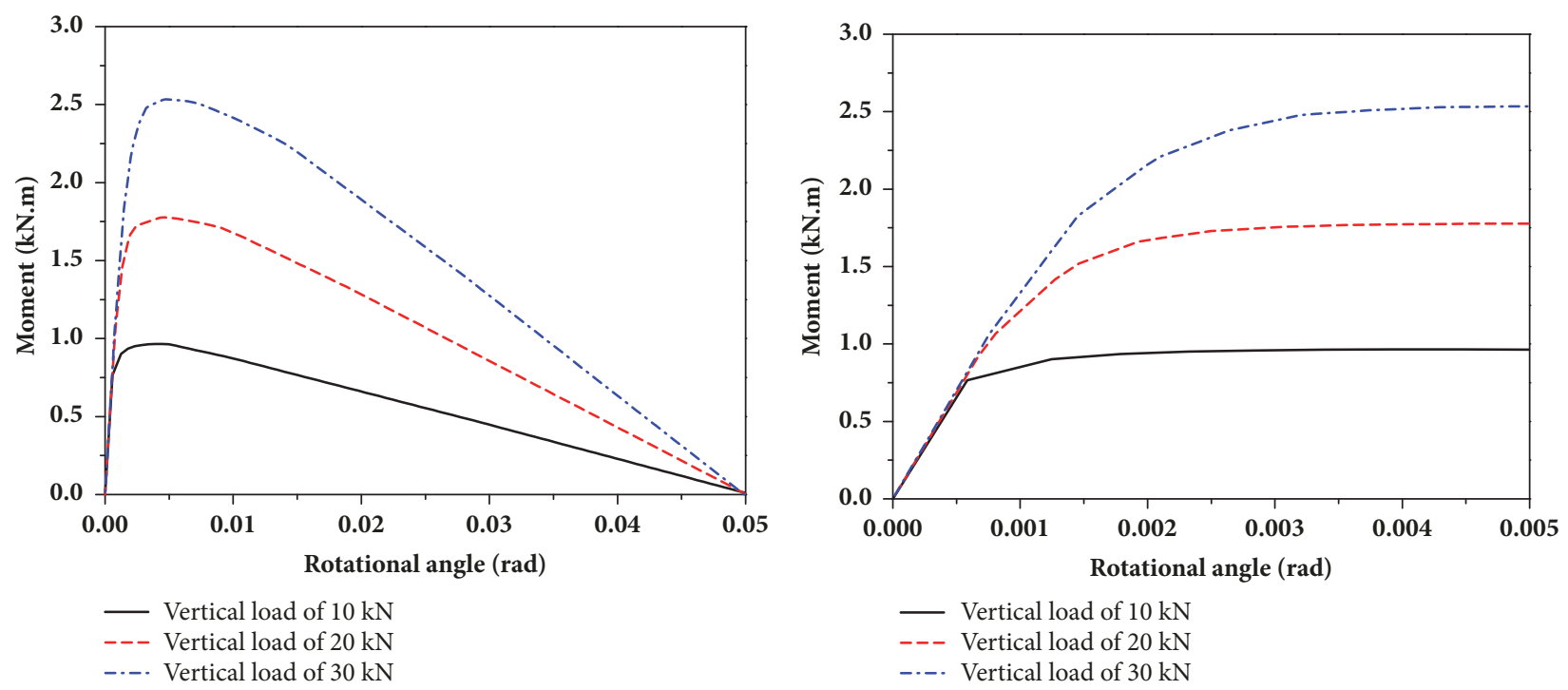

(a)

(b)

FIgURE 6: Moment-rotation curves under different vertical load: (a) global view; (b) local view.

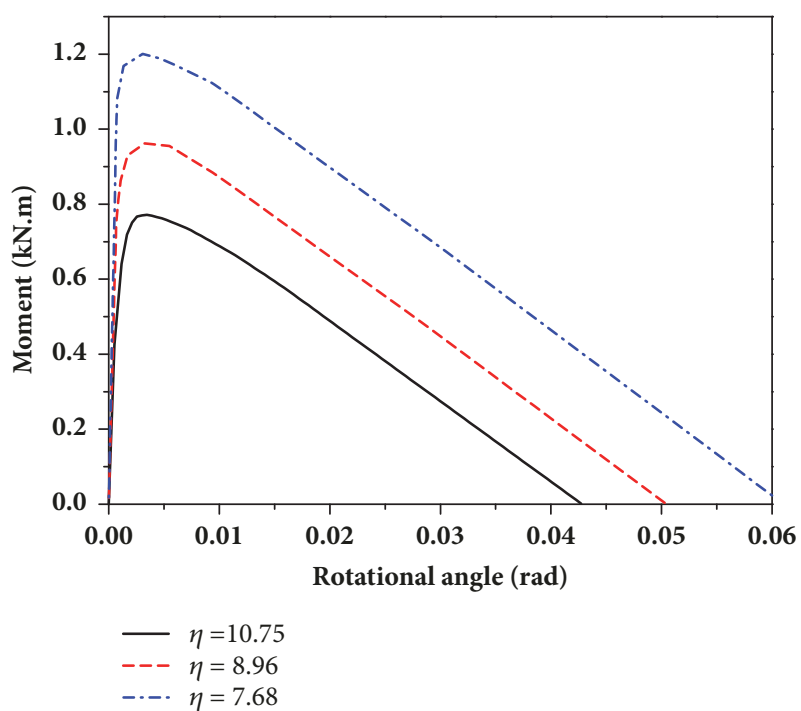

(a)

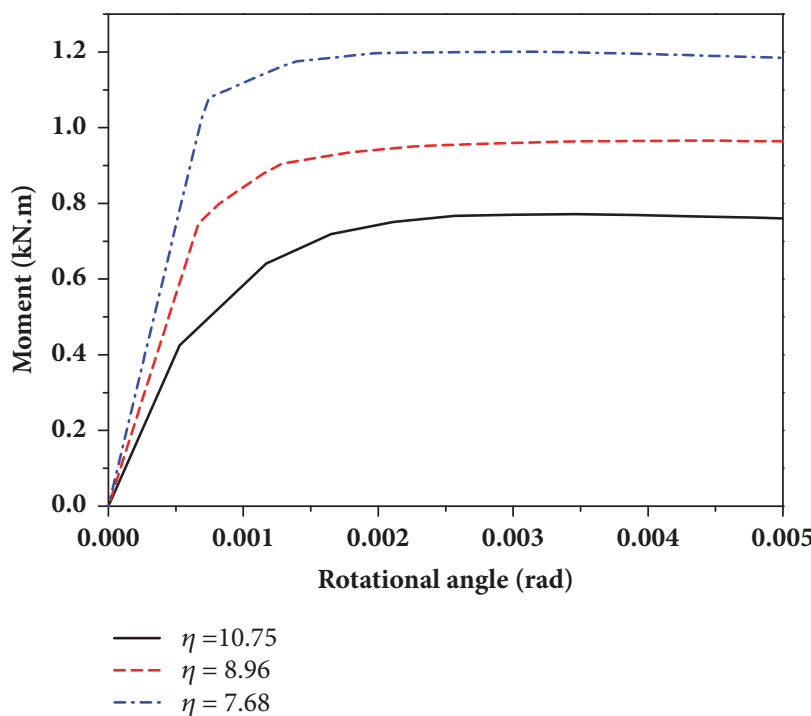

(b)

FIGURE 7: Moment-rotation curves with different column diameter: (a) global view; (b) local view.

$f=\mu N, P^{\prime}=P$, where $P$ is the horizontal load at the column top, as shown in Figure 9.

With the assumption of a rigid column, the column foot rotates around its sectional edge when horizontal load $P$ is applied at the column top. The relationship between the horizontal load and horizontal displacement at the column top may be expressed as follows from equilibrium of moments (Figure 9):

$$
P=\frac{N(0.5 d-s)}{h}=\frac{0.5 N d}{h}-N \theta
$$

where $s=h \theta$ is the horizontal displacement at the column top; $\theta$ is the rotational angle of the joint; $h$ and $d$ are the height and sectional diameter of column, respectively.
The moment-rotation relationship of the CFJ may be given as

$$
M=0.5 N d-N h \theta
$$

The external moment needed to start the rotation of the column foot is given as

$$
M_{i r}=0.5 d N
$$

It is noted that $M_{i r}$ is the theoretical maximum moment $M_{\text {max, rigid }}$ that rotates a rigid column. In fact, the timber column is deformable with certain modulus of elasticity, and the maximum moment $M_{\text {max }}$, deformable should be smaller than $M_{i r}$, as illustrated in Figure 5. 


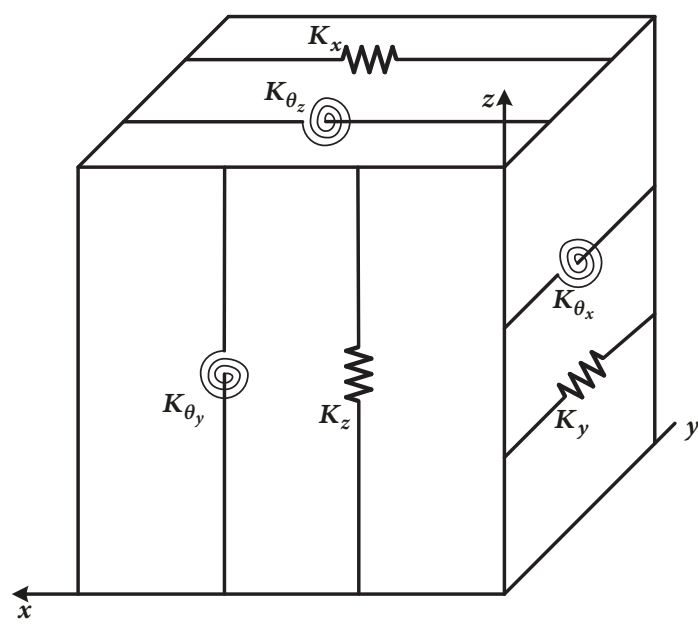

FIGURE 8: 3D spring element model.

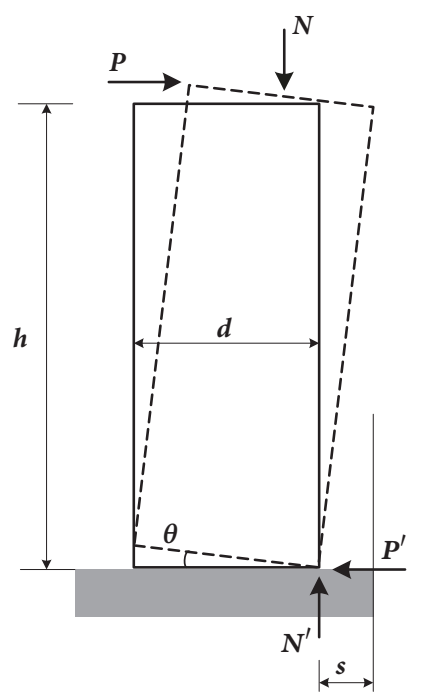

FIGURE 9: Rotational deformation of rigid column.

The range of $\mu$ has been determined experimentally as $[0.3,0.5]$ [10]. Substituting $\mu$ and the dimensions of column (diameter $=240 \mathrm{~mm}$, height $=2150 \mathrm{~mm}$ ) into (2) and (5), it is found that the static frictional resistance is much higher than $P_{i r}=M_{i r} / h$, indicating that the column foot will just rotate without slipping under the horizontal load. This would mean the lateral behavior of the column foot is dominated by the rotational behavior rather than the translation of the column. This observation is also supported by experimental results [15-17]. Therefore, the following assumptions can be made for a CFJ as follows:

(1) The values of three axial stiffness types $K_{x}, K_{y}$, and $K_{z}$ are assumed to be infinite, i.e., $K_{x}=K_{y}=K_{z}=\infty$.

(2) The rotational stiffness types $K_{\theta x}$ and $K_{\theta y}$ are equal for the circular cross section of column with the same rotational behavior about $x$ and $y$ axes.

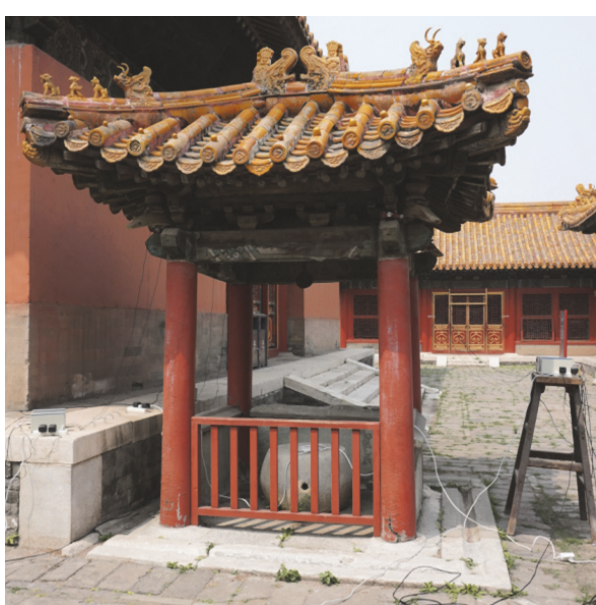

Figure 10: Traditional timber pavilion in the Forbidden City.

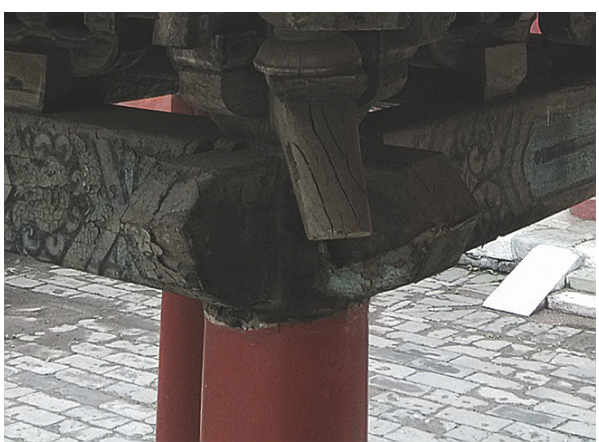

Figure 11: Beam-column connection at the column top.

(3) The column generally does not rotate about its own central axis [17] and the rotational stiffness of $K_{\theta z}$ can be assumed to be infinite, i.e., $K_{\theta z}=\infty$.

The stiffness matrix of the 3D SEM of a CFJ can then be simplified as a model with only one stiffness parameter $K_{\theta x}=$ $K_{\theta y}=K$.

\section{Numerical Study on the Effect of Rotational Stiffness}

5.1. The Structure. The performance of the CFJ in the dynamic analysis of a traditional Chinese timber structure is illustrated with a timber pavilion in the Forbidden City shown in Figure 10. There are four $240 \mathrm{~mm}$ diameter circular columns placed directly on the base stones at the four corners of the structure. The overall dimensions of the structure are $1590 \mathrm{~mm}$ in two orthogonal directions in plan with $3450 \mathrm{~mm}$ total height and $2150 \mathrm{~mm}$ high columns.

5.2. Structural Condition Survey. This structure was built in 1420 and it is typical of timber structures of the Chinese Ming Dynasty. Cross-beams are framed into the top of column in two orthogonal directions (Figure 11) and the moment restraint to the column top in two directions can be considered similar. Some damage, however, can be found in the 


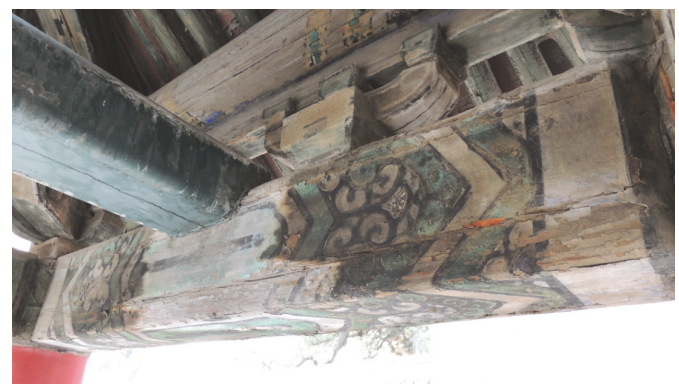

(a)

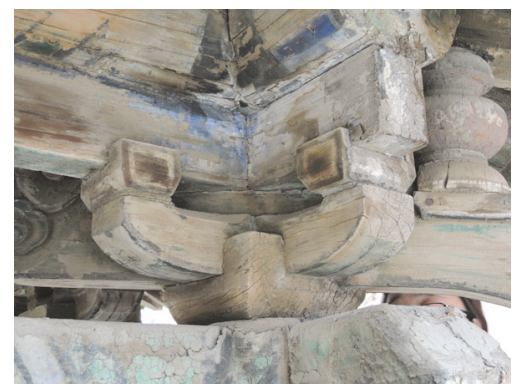

(b)

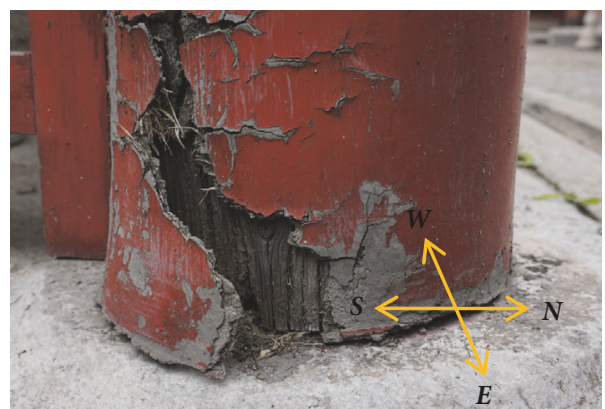

(c)

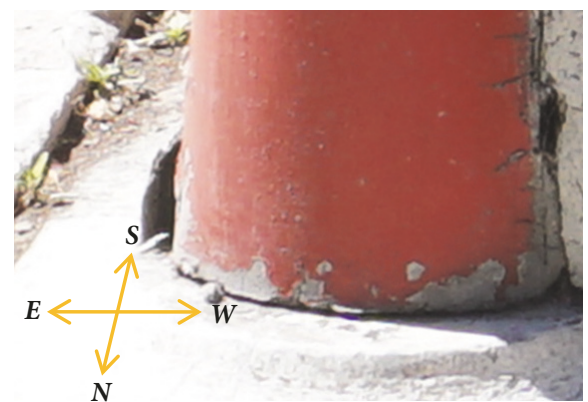

(d)

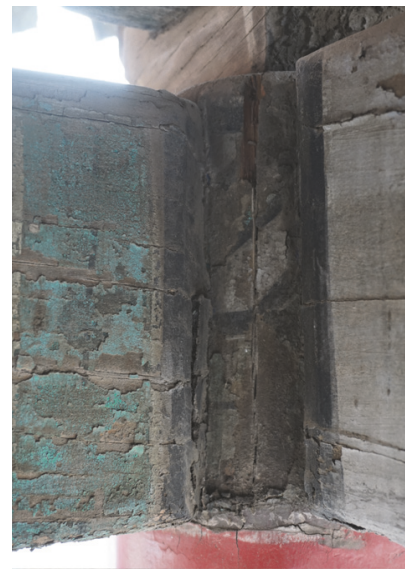

(e)

FIGURE 12: Structural damage phenomena: (a) crack on the surface of the beam; (b) compression deformation of Dou Gong; (c) serious decay of column foot in east side; (d) north side of column foot in relatively good condition; (e) cracks and decay at the column top.

structure due to environmental effects and bioerosion after 600 hundreds years of service. All beams have obvious cracks on the surface parallel to grain (Figure 12(a)). Large compression deformation perpendicular to grain (Figure 12(b)) can be seen in the Dou Gongs. The damaged condition at the column feet is noted different in two orthotropic directions. The protective layer to the timber peeled off on the east and west sides of the column edge (Figure 12(c)) with the inner wood ulcerated and with a reduced effective bearing area. This may result in a reduction of rotational stiffness of the $\mathrm{CFJ}$ in this direction. The column foot is found in a relatively good condition along the north-south direction with slight peeling of the protective layer, as shown in Figure 12(d). There are some cracks and slight decay of timber at the column top (Figure 12(e)), whereas no obvious damage can be found in the mortise-tenon joints at the column top in the two orthotropic directions.

5.3. FEM of the Structure. A component-based FEM of the timber pavilion is prepared in SAP2000 as shown in Figure 13. Some details of the FEM are as follows:

(1) The timber species of the pavilion is hardwood pine. Since no material test is allowed on the structure, the material properties [40] shown in Table 2 are adopted.

(2) Based on survey records on the structure, the configuration of roof and the dimensions of different components are obtained and the estimated total

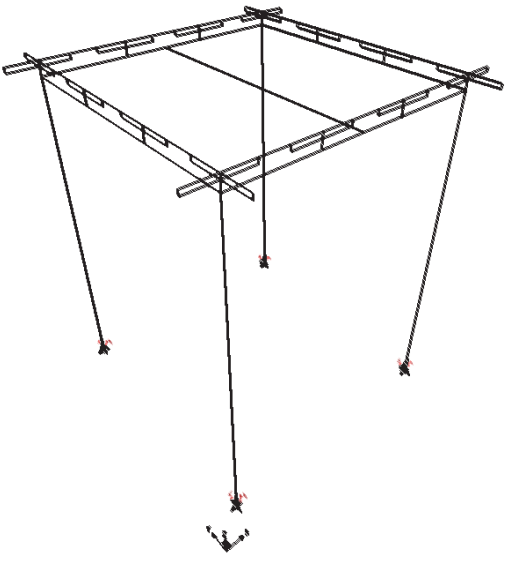

FIGURE 13: FEM of timber pavilion.

mass of roof is $3471 \mathrm{~kg}$. A lump mass approach [36] is adopted with a distribution shown in Figure 14.

(3) The three pieces of brick walls near the pavilion were built after the construction of the timber structure and these walls do not bear vertical load. There are obvious gaps between the columns and the walls. Therefore, the presence of these walls is not included in the dynamic analysis of the structure. 


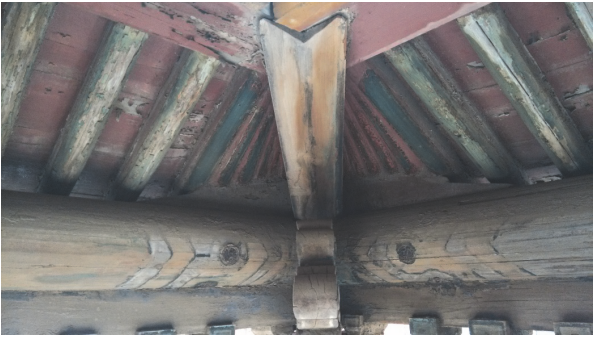

(a)

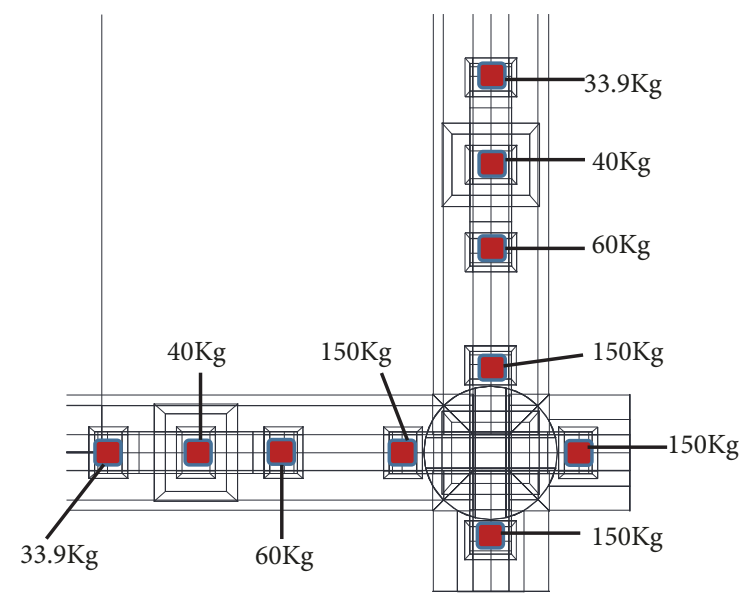

(b)

FIGURE 14: Roof of the structure: (a) picture of roof at corner; (b) simplification of roof mass distribution.

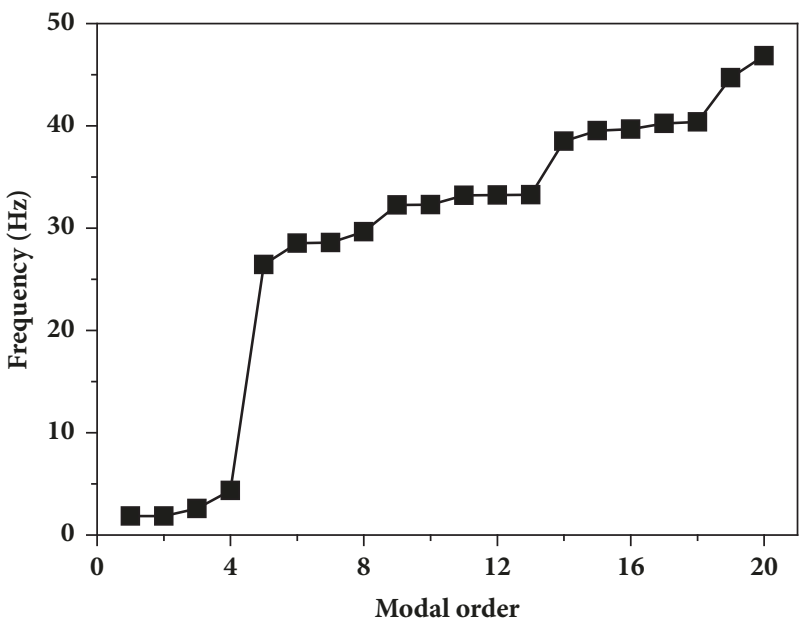

FIGURE 15: Distribution of natural vibration frequency.

(4) The CFJ is modeled as a semirigid connection with the proposed 3D SEM with a rotational stiffness $K$ as stated in Section 4.

5.4. Modal Analysis of the Structure. When the vertical load on top of the column is $867.75 \mathrm{~kg}$ from the self-weight of roof, the rotational stiffness of the CFJ is calculated as $K=858$ $\mathrm{kN}=\mathrm{m} / \mathrm{rad}$ from the analysis in Section 3.2 for the undamaged column foot. The first twenty modal frequencies are shown in Figure 15.

The first four modal frequencies are relatively small. The 1st and 2nd modal frequencies are close to each other due to the geometrical symmetric arrangement of the structure. The corresponding mode shapes are horizontal along the $x$ and $y$ axes. The 3rd mode is torsional and the first three mode shapes are shown in Figure 16. There is a large gap between the 4 th and 5 th modal frequencies followed by the higher frequencies which are increasing gradually with the modal order.
TABLE 3: Effect of rotational stiffness of CFJ on structural natural frequency.

\begin{tabular}{lccc}
\hline$K(\mathrm{~N} . \mathrm{m} / \mathrm{rad})$ & \multicolumn{3}{c}{ Frequency $(\mathrm{Hz})$} \\
& The 1st order & The 2nd order & The 3rd order \\
\hline 0 & 0.5234 & 0.5250 & 1.6854 \\
$10^{1}$ & 0.5234 & 0.5250 & 1.6854 \\
$10^{2}$ & 0.5238 & 0.5254 & 1.6856 \\
$10^{3}$ & 0.5281 & 0.5296 & 1.6871 \\
$10^{4}$ & 0.5684 & 0.5699 & 1.7029 \\
$10^{5}$ & 0.8652 & 0.8662 & 1.8476 \\
$10^{6}$ & 1.9486 & 1.9491 & 2.6673 \\
$10^{7}$ & 3.1777 & 3.1781 & 3.8561 \\
$10^{8}$ & 3.4968 & 3.4971 & 4.1858 \\
$10^{9}$ & 3.5344 & 3.5347 & 4.2251 \\
$10^{10}$ & 3.5382 & 3.5386 & 4.2291 \\
$10^{11}$ & 3.5386 & 3.539 & 4.2295 \\
$10^{12}$ & 3.5386 & 3.539 & 4.2296 \\
$\infty$ & 3.5386 & 3.539 & 4.2296 \\
\hline
\end{tabular}

The low-order modes often play an important role in the structural dynamic analysis of the traditional Chinese timber structure [27-32], and this paper mainly focuses on the effect of rotational stiffness of the CFJ on the first three modes in the following discussions.

5.5. Effect of Rotational Stiffness of CFJ on the Modal Frequency. When the rotational stiffness of CFJ increases from $K=0$ (hinged connection) to $K=\infty$ (rigid connection), the variations of the first three modal frequencies of the structure are shown in Table 3. The rotational stiffness $K$ is found to have notable influence on the natural frequency of the structure, and the first three modal frequencies increase with an increase in the rotational stiffness of the CFJ. The relationship of the fundamental frequency and rotational stiffness $K$ is shown in Figure 17, and the fundamental frequency is found varying much over a sensitive range of 


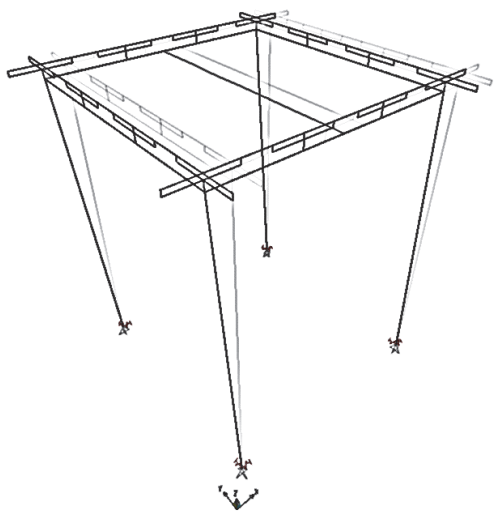

(a)

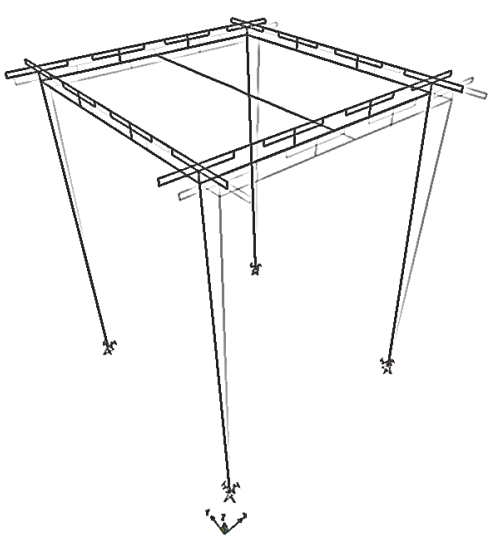

(b)

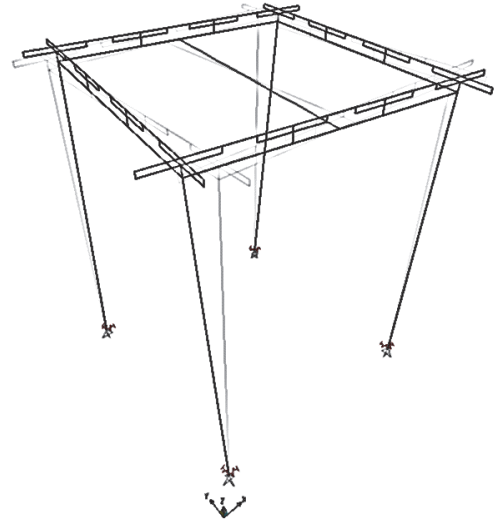

(3)

Figure 16: Mode shapes of the first 3 orders: (a) 1st mode; (b) 2nd mode; (3) 3rd mode.

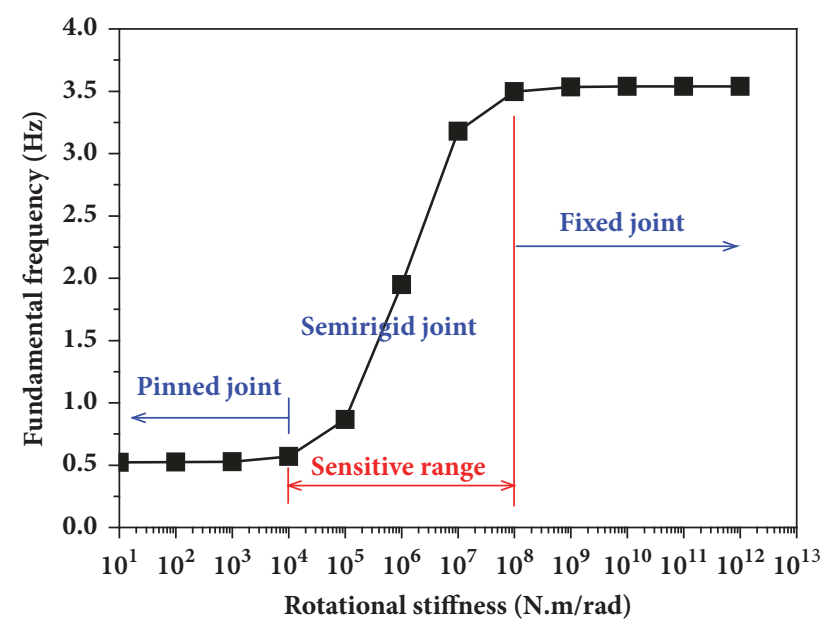

FIGURE 17: The relationship of fundamental frequency and rotational stiffness of CFJ.

rotational stiffness of CFJ from $10^{4}$ to $10^{8} \mathrm{~N}=\mathrm{m} / \mathrm{rad}$. Hence, the CFJ may be regarded as a pinned joint when the $K<10^{4}$ $\mathrm{N}=\mathrm{m} / \mathrm{rad}$ and a fixed joint when $K>10^{8} \mathrm{~N}=\mathrm{m} / \mathrm{rad}$.

\section{Experimental Study of the Effect of Rotational Stiffness}

A field test was conducted on the aforementioned timber pavilion (Figure 10). The objective of the test is to obtain the natural frequencies of the timber structure.

6.1. Field Test Configuration. This timber pavilion is a listed heritage and a protected cultural relic, and therefore mechanical vibration which may lead to potential damage in the structure was not allowed. Ambient excitation is adopted for the dynamic test similar to the many tests in other historical timber structures in China. The test structure is in a closed area in the Forbidden City not open to the public. The test was carried out on June 25, 2016, with a low wind speed in the surrounding, and the ambient excitation may be considered coming mainly from activities in the surrounding environment. The sampling frequency is $128 \mathrm{~Hz}$ and the sampling duration is 30 minutes.

Eight accelerometers were placed horizontally at the top of the four columns in two orthotropic directions, to measure the horizontally vibration of the structure. The sensor layout is shown in Figure 18. The acceleration responses were collected using model KD1300 accelerometers, model KD5008 charge amplifiers, and model INV3060A dynamic data acquisition system as shown in Figure 19.

6.2. Test Results and Discussions. The modal analysis was conducted with the Hilbert-Huang transform (HHT) method [42] to obtain the modal frequency and vibration mode of the structure as shown in Table 4.

The mode shapes of the first three vibration modes are similar to those shown in Figure 16 with small differences in the amplitude. The first two modes are vibration in the east-west and north-south directions, respectively, and the 3 rd mode is torsional. The 1st- and 2nd-order frequencies should be almost equal since the structure is symmetric in two orthotropic directions as noted in Section 5. Table 4, however, shows that the 1st and 2 nd modal frequencies of the pavilion are $0.74 \mathrm{~Hz}$ and $1.25 \mathrm{~Hz}$, respectively.

According to records of the structural condition survey, the condition of the connection at the column top in both directions is similar (Figure 12(e)). However, the decayed condition of column foot is different in east-west and northsouth directions (Figures 12(c) and 12(d)), and this reduces the effective cross-sectional area at the column foot leading to different degradation of rotational stiffness of CFJ in the two directions. It should be noted that the rotational stiffness of CFJ about the E-W and N-S directions may not be equal with uneven decay and degradation in the joint. The 1st and 2nd modal frequencies of the structure, i.e., $0.74 \mathrm{~Hz}$ and 1.25 $\mathrm{Hz}$, are within the sensitive range as shown in Figure 17, indicating that the CFJ of the timber pavilion should be regarded as a semirigid connection in structural analysis.

The rotational stiffness of CFJ is found by trial and error with the fundamental modal frequency of the real structure. If only degradation of CFJ exists in the structure, 


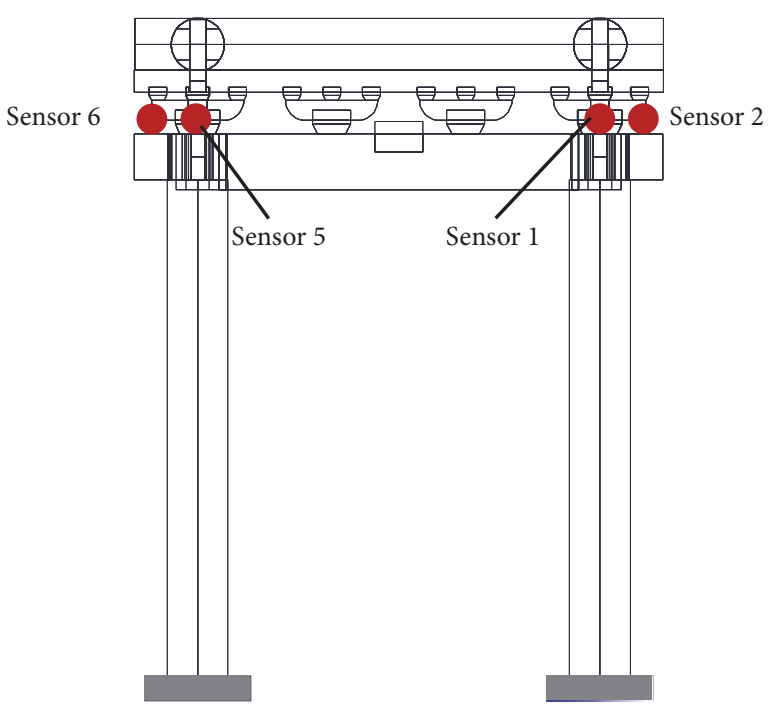

(a)

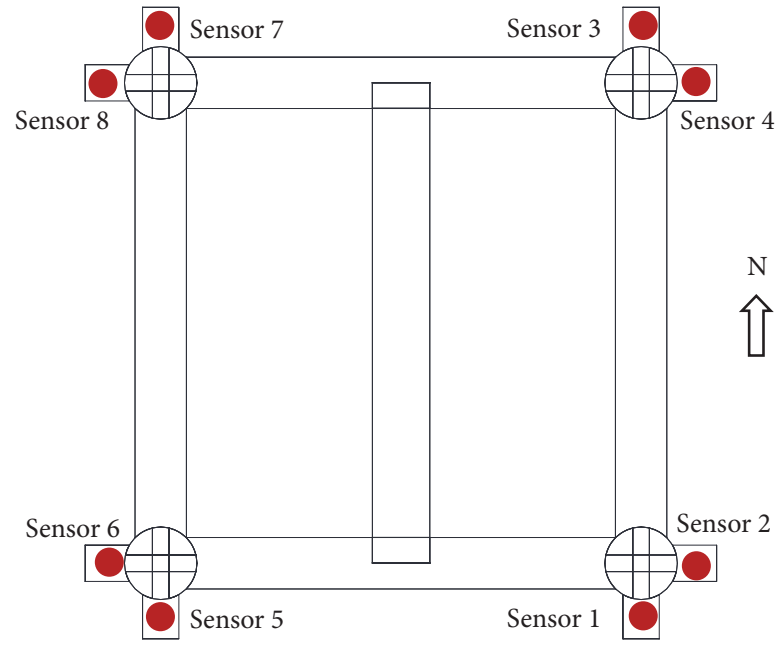

(b)

FIGURE 18: Arrangement of sensors: (a) elevation view; (b) plan view.

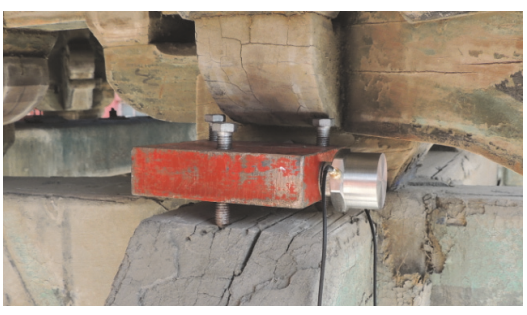

(a)

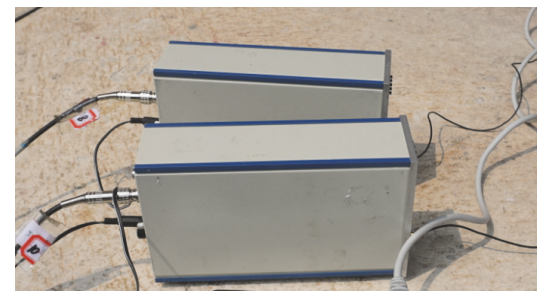

(b)

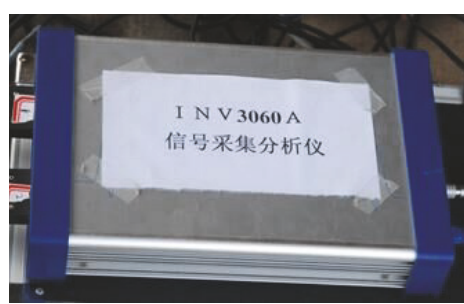

(c)

FIGURE 19: Field test equipment: (a) accelerometer; (b) amplifier; (c) data acquisition system.

the rotational stiffness of CFJ about E-W and N-S directions may be determined as $54.1 \mathrm{kN}=\mathrm{m} / \mathrm{rad}$ and $296.9 \mathrm{kN}=\mathrm{m} / \mathrm{rad}$, respectively, indicating a reduction of $6.3 \%$ and $34.6 \%$ rotational stiffness for the east-west direction and north-south direction, respectively, compared to that without damage. The decay of column foot (Figure 12(c)) is often noted in the condition survey with traditional Chinese timber structures. The degradation of rotational stiffness of CFJ will decrease the overall structural stiffness of the structure. It is therefore necessary to correctly consider this effect in the condition assessment of traditional Chinese timber structures.

\section{Conclusions}

The following conclusions may be drawn from the above studies:

(1) When under increasing horizontal load, the restoring moment of CFJ increases but with decreasing rotational stiffness and increasing rotational angle. The moment-rotation curve exhibits characteristic of negative stiffness after the restoring moment exceeds the maximum value.
(2) The greater the vertical load acting on top of the column, the larger the ultimate moment capacity of the CFJ.

(3) The initial rotational stiffness and ultimate moment capacity decrease with an increase in the ratio of column height to diameter.

(4) The CFJ should be regarded as a semirigid connection with certain rotational stiffness in the analysis of timber structures similar to the timber pavilion studied in this paper.

(5) The variation of rotational stiffness of CFJ has an obvious effect on the natural frequencies of traditional Chinese timber structure, and the sensitive range is from $10^{4}$ to $10^{8} \mathrm{~N}-\mathrm{m} / \mathrm{rad}$ for the structure studied.

(6) The field experiment with different orientation of decay at the column foot of the structure confirms that the of rotational stiffness of CFJ has a notable influence on the dynamic characteristics of the traditional timber structure.

This study aims to provide a useful reference, from a structural point of view, for the safety evaluation and preservation of traditional Chinese timber structures. Different 
TABLE 4: Modal parameters of pavilion.

Structural
modal

Note: abbreviated letters E, W, S, and N denote the directions of east, west, south, and north, respectively.

degrees of damage are often found in column foot with reduced cross section influencing the stability and safety of these heritage buildings. How to correctly assess the effect of timber decay on the rotational behavior of a CFJ needs further research.

\section{Data Availability}

The data used to support the findings of this study are included within the article.

\section{Conflicts of Interest}

The authors declare that there are no conflicts of interest regarding the publication of this paper.

\section{Acknowledgments}

This work is supported by the Beijing Natural Science Foundation of China (Grant no. 8151003) and the National Natural Science Foundation of China (Grant nos. 51422801 and 51338001). The authors would also like to acknowledge the research project funding of the National Key Technology R\&D Program (Grant no. 2015BAK01B02) and the 111 Project of China (Grant no. B13002). The comments and help from Professor Law Siu-seong in polishing the English usage of this paper are also acknowledged.

\section{References}

[1] S. Qin and N. Yang, "Investigation of damage condition of Chinese ancient timber buildings," in Proceedings of the 14th International Symposium on Structural Engineering, pp. 13901395, Beijing, China, October 2016.

[2] T. Li and H. Qin, "Structural analysis and repair of Yingxian wooden tower," Engineering Mechanics, vol. 22, sup., pp. 199212, 2005

[3] N. Yang, P. Li, S. S. Law, and Q. Yang, "Experimental research on mechanical properties of timber in ancient tibetan building," Journal of Materials in Civil Engineering, vol. 24, no. 6, pp. 635643, 2012.
[4] S. C. Liang, A Pictorical History of Chinese Architecture, MIT Press, Cambridge, Mass, USA, 1984.

[5] J. Li, Ying Zao Fa Shi, Royal Press, Kaifeng, China, 1100, in ancient Chinese.

[6] B. J. Ma, Wood Construction Techniques of Chinese Ancient Architecture, Science Press, Beijing, China, 1991.

[7] T. Wang, Static Mechanics of Ancient Timber Structures, Historical Relic Press, Beijing, China, 1992.

[8] H. Zhao, F. Zhang, J. Xue, Q. Xie, X. Zhang, and H. Ma, "Research review on structural performance of ancient timber structure," Journal of Building Structures, vol. 33, no. 8, pp. 1-10, 2012.

[9] Z. Chen, E. Zhu, and J. Pan, "A review on structural mechanics of Chinese ancient wood structures," Advances in Mechanics, vol. 42, no. 5, pp. 644-654, 2012 (Chinese).

[10] P. Zhang, Study on structure and its seismic behavior development of Chinese ancient timber structure building [Ph.D thesis], Xian University of Architecture Technology, Xian, 2003.

[11] K. Yao and H.-T. Zhao, "Study on the mechanism of sliding friction shock isolation between timber column and plinth in historical buildings," Gongcheng Lixue/Engineering Mechanics, vol. 23, no. 8, pp. 127-159, 2006.

[12] J. Xue, H. Zhao, and P. Zhang, "Study on the seismic behaviors of Chinese ancient wooden building by shaking table test," China Civil Engineering Journal, vol. 37, no. 6, pp. 6-11, 2004.

[13] D. Lee, Y. Araki, T. Endo, N. Yoshida, and K. Uetani, "Modelling of column base for traditional timber buildings based on local compression experiments at contact surface between column base and foundation stone," Journal of Structural and Construction Engineering, vol. 74, no. 639, pp. 865-872, 2009.

[14] M. Maeno, Y. Suzuki, T. Ohshita, and A. Kitahara, "Seismic response characteristics of traditional wooden frame by fullscale dynamic and static tests," in Proceedings of the 13th World Conference on Earthquake Engineering, Vancouver, Canada, August 2004.

[15] F. Zhang, H. Zhao, J. Xue, Q. Xie, Y. Sui, and Z. Luo, "Lateral load-resisting analysis and experimental verification of ancient timber column-frame based on swing-columns principle," Industrial Construction, vol. 43, no. 10, pp. 55-60, 2013.

[16] T. Maeda, "Column rocking behavior of traditional wooden buildings in Japan," in Proceedings of the 10th World Conference on Timber Engineering 2008, pp. 1372-1378, Japan, June 2008. 
[17] J. He, J. Wang, and Q. Yang, “Theoretical and experimental analysis on mechanical behavior of column in traditional timber structure during rocking," Journal of Engineering Mechanics, vol. 34, no. 11, pp. 50-58, 2017.

[18] J. He and J. Wang, "Theoretical model and finite element analysis for restoring moment at column foot during rocking," Journal of Wood Science, vol. 64, no. 2, pp. 97-111, 2018.

[19] Z. Chen, E. Zhu, F. Lam, and J. Pan, "Structural performance of Dou-Gong brackets of Yingxian Wood Pagoda under vertical load - An experimental study," Engineering Structures, vol. 80, pp. 274-288, 2014.

[20] Q. Zhou, N. Yang, and Q. Chun, "Experiments on seismic performance of bracket sets of second eave of Taihe Palace in the Forbidden City," Dongnan Daxue Xuebao (Ziran Kexue Ban)/Journal of Southeast University (Natural Science Edition), vol. 47, no. 1, pp. 150-158, 2017.

[21] J. Xue, P. Lu, and X. Dong, "Finite element analysis on the vertically mechanical behavior of the skewed Dou-Gong in ancient timber buildings by ABAQUS program," Journal of Xian University of Architecture Technology, vol. 49, no. 1, p. 13, 2017.

[22] C. Chen, H. Qiu, and Y. Lu, "Flexural behaviour of timber dovetail mortise-tenon joints," Construction and Building Materials, vol. 112, pp. 366-377, 2016.

[23] J. Xue, Y. Li, H. Xia, and Y. Sui, "Experimental study on seismic performance of dovetail joints with different loose degrees in ancient buildings," Jianzhu Jiegou Xuebao/Journal of Building Structures, vol. 37, no. 4, pp. 73-79, 2016.

[24] Q. Chun, W. Lü, J. Wang, and J. Pan, "Mechanical properties of typical mortise-tenon joints of post and lintel construction and column and tie construction of timber buildings in Jiangsu Province and Zhejiang Province," Dongnan Daxue Xuebao (Ziran Kexue Ban)/Journal of Southeast University (Natural Science Edition), vol. 45, no. 1, pp. 151-158, 2015.

[25] Q. Xie, W. Xiang, B. Du, and P. Zheng, "Study on seismic behavior degradation of damaged "Dougong" joint built with fork column of Chinese ancient timber structure," Tumu Gongcheng Xuebao/China Civil Engineering Journal, vol. 47, no. 12, pp. 4955, 2014.

[26] Q. Xie, B. Du, S. Li, W. Xiang, and P. Zheng, “Tests for aseismic behaviors of damaged dovetail mortise-tenon joints of ancient timber buildings," Journal of Vibration and Shock, vol. 34, no. 4, pp. 165-170, 2015.

[27] T. Li, J. Wei, S. Zhang, and S. Li, "Experiment and analysis of vibration characteristics of Yingxian wooden tower," Engineering Mechanics, vol. 22, no. 1, pp. 141-146, 2005.

[28] D. P. Fang, S. Iwasaki, M. H. Yu, Q. P. Shen, Y. Miyamoto, and H. Hikosaka, "Ancient Chinese timber architecture. I: Experimental Study," Journal of Structural Engineering, vol. 127, no. 11, pp. 1348-1357, 2001.

[29] J. Wei, T. Li, and S. Li, "Dynamic Characteristic Analysis of Kwanyin Pavilion in Doule Temple," Journal of Taiyuan University of Technology, vol. 33, no. 4, pp. 430-432, 2002.

[30] H. Hu, Modal parameters identification and vibration evaluation of timber structure [Master thesis], Beijing Jiaotong University, Beijing, 2017.

[31] B. Chen, Q. Yang, K. Wang, and L. Wang, "Full-scale measurements of wind effects and modal parameter identification of Yingxian wooden tower," Wind and Structures, An International Journal, vol. 17, no. 6, pp. 609-627, 2013.

[32] Y. Zhang, N. Zhang, Y. Cao, and H. Xia, "A Prediction Method of Historical Timber Buildings' Vibrations Induced by Traffic Loads and Its Validation," Shock and Vibration, vol. 2017, 2017.
[33] L. Dai, N. Yang, S. S. Law, and Q. Yang, "Modal parameter identification and damping ratio estimation from the fullscale measurements of a typical Tibetan wooden structure," Earthquake Engineering and Engineering Vibration, vol. 15, no. 4, pp. 681-695, 2016.

[34] Y. Sui, Analysis on energy dissipation mechanism and dynamic characteristic for Chinese ancient timber buildings [Ph.D thesis] [Ph.D. thesis], Xian University of Architecture Technology, Xian, 2009.

[35] Y. Sui, H. Zhao, J. Xue, X. Zhang, and Y. Liu, "A study on Chinese ancient timber structures by shaking table test," Jianzhu Jiegou Xuebao/Journal of Building Structures, vol. 31, no. 2, pp. 35-40, 2010.

[36] D. P. Fang, S. Iwasaki, M. H. Yu, Q. P. Shen, Y. Miyamoto, and H. Hikosaka, "Ancient Chinese timber architecture. II: dynamic characteristics," Journal of Structural Engineering, vol. 127, no. 11, pp. 1358-1363, 2001.

[37] Q. Zhou, W. Yan, X. Zhou, and J. Ji, "Vibration characters and seismic response of Chinese ancient buildings," Journal of Beijing University of Technology, vol. 36, no. 1, pp. 13-17, 2010.

[38] Z. Chen, Behavior of typical joints and the structure of Yingxian wood pagoda [Ph.D thesis] [Ph.D. thesis], Harbin Institute of Technology, Harbin, 2011.

[39] T. Zhang and F. Lu, "Dynamic structural characteristics of an ancient timber tower," Engineering Mechanics, vol. 21, no. 1, pp. 81-86, 2004.

[40] China Southwest Architectural Design and Research Institute, Code for Design of Timber Structures, China Architecture \& Building Press, Beijing, China, 2005.

[41] W.-F. Chen and N. Kishi, "Semirigid steel beam-to-column connections: Data base and modeling," Journal of Structural Engineering (United States), vol. 115, no. 1, pp. 105-119, 1989.

[42] J. Chen and Y. Xu, "Application of HHT for modal parameter identification to civil structures," Journal of Vibration Engineering, vol. 16, no. 3, pp. 383-388, 2003. 


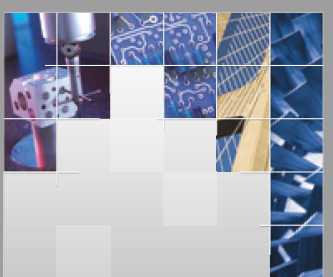

\section{Enfincering}
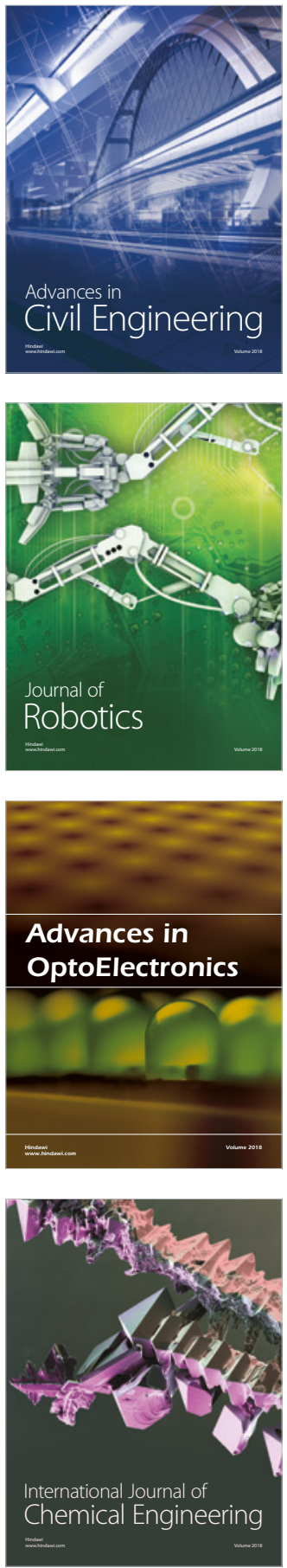

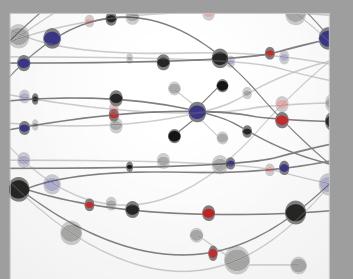

\section{Rotating \\ Machinery}

The Scientific World Journal

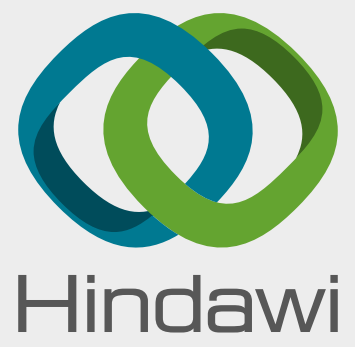

Submit your manuscripts at

www.hindawi.com
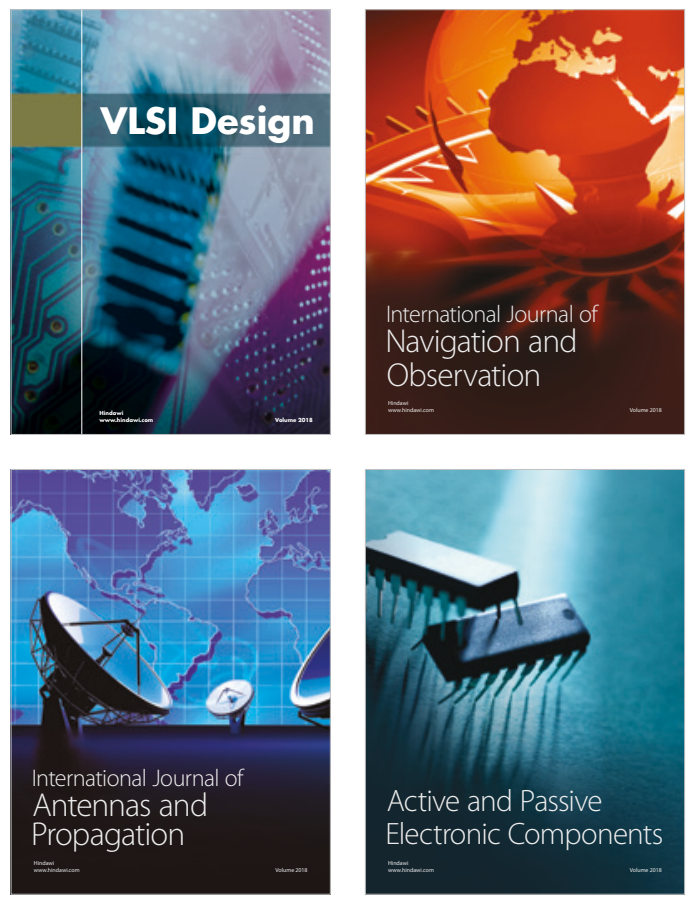
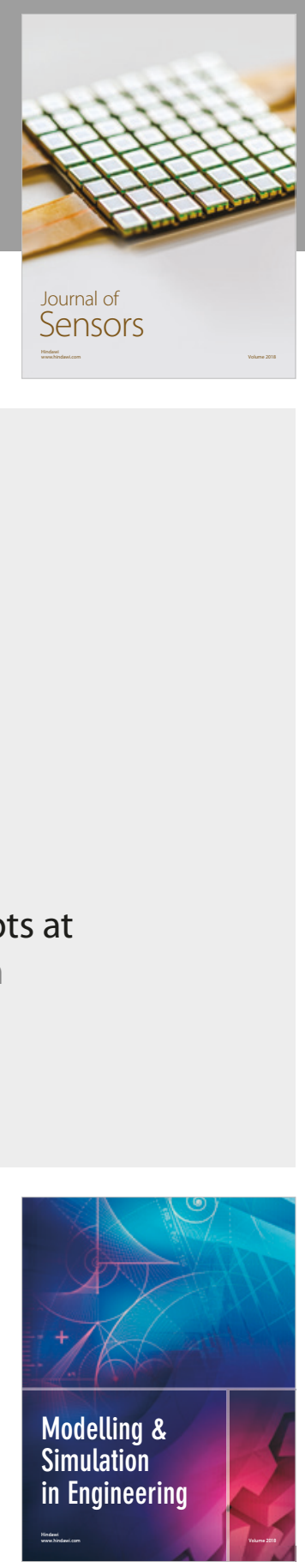

\section{Advances \\ Multimedia}
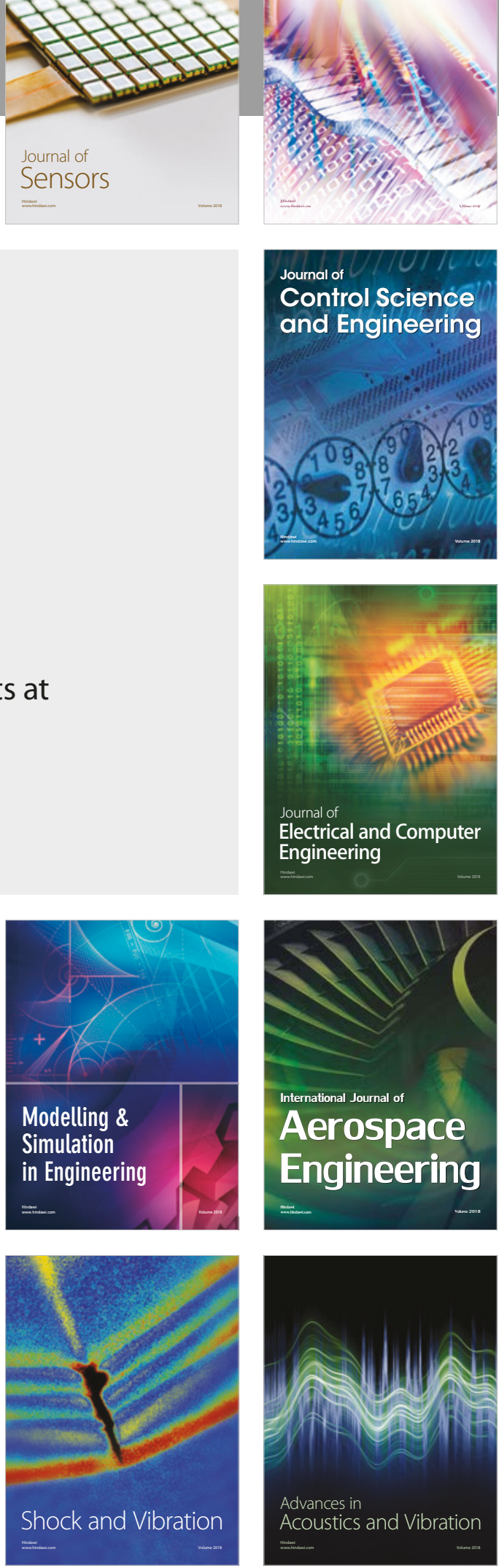